Article

\title{
Bioactive Bilayer Glass Coating on Porous Titanium Substrates with Enhanced Biofunctional and Tribomechanical Behavior
}

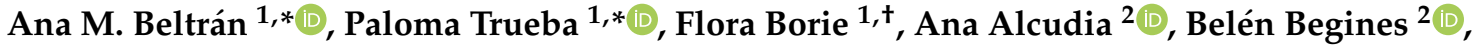 \\ José A. Rodriguez-Ortiz ${ }^{1}$ and Yadir Torres ${ }^{1}$ (D) \\ 1 Departamento de Ingeniería y Ciencia de los Materiales y del Transporte, Escuela Politécnica Superior, \\ Universidad de Sevilla, 41011 Seville, Spain; flora.borie@gmail.com (F.B.); jarortiz@us.es (J.A.R.-O.); \\ ytorres@us.es (Y.T.) \\ 2 Departamento de Química Orgánica y Farmacéutica, Facultad de Farmacia, Universidad de Sevilla, \\ 41012 Seville, Spain; aalcudia@us.es (A.A.); bbegines@us.es (B.B.) \\ * Correspondence: abeltran3@us.es (A.M.B.); ptrueba@us.es (P.T.) \\ + Current address: Centre Scientifique et Technique du Bâtiment, 77420 Champs-sur-Marne, France.
}

check for updates

Citation: Beltrán, A.M.; Trueba, P.; Borie, F.; Alcudia, A.; Begines, B.; Rodriguez-Ortiz, J.A.; Torres, Y. Bioactive Bilayer Glass Coating on Porous Titanium Substrates with Enhanced Biofunctional and Tribomechanical Behavior. Coatings 2022, 12, 245. https://doi.org/ 10.3390/coatings12020245

Academic Editor: Sara Ferraris

Received: 17 January 2022

Accepted: 11 February 2022

Published: 14 February 2022

Publisher's Note: MDPI stays neutral with regard to jurisdictional claims in published maps and institutional affiliations.

Copyright: (C) 2022 by the authors. Licensee MDPI, Basel, Switzerland. This article is an open access article distributed under the terms and conditions of the Creative Commons Attribution (CC BY) license (https:// creativecommons.org/licenses/by/ $4.0 /)$.

\begin{abstract}
The use of porous titanium samples fabricated by space-holder powder metallurgy with bioactive coatings has already been reported to prevent resorption of the bone surrounding the implant and improve osseointegration, respectively. However, the presence of pores as well as the poor adherence and the brittle behavior inherent to glassy coatings affect the service behavior of implants fabricated from these samples. Therefore, they need to be optimized. In this work, 50 vol. $\%$ of porosity titanium substrates were manufactured with different pore range size (100-200 and $355-500 \mu \mathrm{m})$ spacer particles and coated with a bilayer of bioactive glasses (45S5/1393). The effect of the pores on the tribomechanical properties and infiltration of the bioactive glass 1393 along with the bioactivity of the bioactive glass $45 \mathrm{~S} 5$ were evaluated by instrumented micro-indentation and scratch tests and the formation of hydroxyapatite in simulated body fluid. The results obtained were very promising as potential implants for the replacement of small tumors in cortical bone tissues, mainly due to the smaller pores that present an improved biomechanical and biofunctional balance.
\end{abstract}

Keywords: porous titanium; bioglass coating; tribo-mechanical behavior; bioactivity

\section{Introduction}

The area of implant manufacture is attracting growing attention due to the result of a longer life expectancy (i.e., Spain and Italy had the highest life expectancy among EU countries, reaching over 83 years in 2018). However, living longer has associated the need for tissue or prosthesis replacements if they fail, for reasons such as trauma, unhealthy lifestyle, or weakening due to calcium deficiency. Furthermore, it is well known that implants for young people are subject to a higher mechanical load for longer periods of time, so the development of new strategies and methodologies to improve knowledge about these devices plays a crucial role in the field. In this context, more specialized and multidisciplinary research is needed to implement prototypes and in vivo performance of small implantable devices to replace damaged bone tissues in small bone-localized tumors [1,2].

Pure titanium is one of the most appropriate materials for cortical bone replacement due to its excellent properties regarding mechanical, chemical, and physical properties, such as high specific strength, corrosion resistance, low density, and biocompatibility/biofunctional behavior. Unfortunately, the widely described stress-shielding phenomenon associated with bone resorption, caused by the different Young's modulus between bone and implant, compromises the reliability of implants $[3,4]$. The use of porous substrates could implement stress-shielding behavior. At this point, the space-holder manufacturing technique described 
for the first time in 2001 by Wen et al. [5] represents a highly adequate and convenient methodology to overcome the drawbacks of bone matching moduli to fabricate porous titanium substrates, among other techniques previously described in the literature, such as additive manufacturing methods or even foaming technologies [6-8]. Although the space-holder technique has been extensively used due to its reliability, versatility, and affordable economic expenses, the pores generated should have a balanced amount, size, and morphology to avoid fracture or fatigue associated with undesirable tribomechanical behavior. However, these structures have been shown to be ideal for promoting bone ingrowth towards the bottom of the implant in addition to adhesion to the coating. Furthermore, although titanium induces poor osseointegration, the use of bioactive coatings has overcome the problem of deficiency in stimulation for adequate bone regeneration $[9,10]$. Among the different coatings that have been described for this purpose, organic frames such as biopolymers, inorganic salts such as hydroxyapatite (HA), or bioactive glasses are very promising [11-13].

Bioactive coatings improve not only bone formation but also adhesion and fixation and should be biocompatible, nontoxic, non-carcinogenic, or allergenic, and due to their flexibility to adjust their composition, they present an extraordinary versatility [14-19]. In this sense, they have been widely used for biomedical applications in tissue regeneration or as a part of matrixes for the release of smart and targeted drugs [20,21]. They could also be classified into three categories: bioactive, bioinert, and bioresorbable coatings, exhibiting durability and resistance to biological fluids, and in many cases could be modified to improve antibacterial behavior, cell adhesion, and proliferation. Among the materials that have these characteristics and have been widely used as titanium coatings, hydroxyapatite and bioactive glasses are very attractive. In 1969, Hench et al. [22] produced the first bioglass or bioactive glass that was used to attach to bone without rejection or biological tissue injury, mediated by 11 successive chemical reactions to stimulate effective bonds between bone and glassy material due to the formation of a wollastonite layer that evolves to hydroxycarbonate apatite, which is the main component of mineral bone [22]. Furthermore, these materials have been proven to possess antimicrobial characteristics and appropriate tensile and compression strength [23]. Surprisingly, 1 or 2 days after implantation, growth factors begin to stimulate cell division, mitosis, and extracellular matrix protein production, and in 6 to 12 days, osteocytes are incorporated into a matrix of collagen-hydroxycarbonate apatite that promotes osseointegration that could be mimicked under in vitro conditions using simulated body fluid (SBF) at $37^{\circ} \mathrm{C}$ for $14-28$ days [24,25]. The surface morphology evolution of submerged samples could be analyzed using Fourier transform infrared spectroscopy (FTIR), X-ray diffraction, inductive coupled plasma, and scanning electron microscopy (SEM) techniques. However, maintaining these coatings to cover the metal efficiently remains a challenge, as well as trying to match the expansion coefficients between the metal and the bioglass (BG). In this sense, silicate-based bioglasses, such as BG 45S5 or BG 1393, show more interesting biological behavior compared to alternatives of borate or phosphate [26-29]. In particular, BG $45 \mathrm{S5}$ has a faster kinetic to stimulate hydroxyapatite for bone growth to create an efficient implant interface and has better bioactivities than other BGs [21,30-34]. In this sense, in vivo bioactivity of BG $45 S 5$ has been widely reported in the literature as a useful tool to accelerate and heal damaged tissues to efficiently regenerate bones [35-40].

In the case of BG 1393, although bioactivity is lower, adherence is better, as the thermal expansion coefficient (CTE) is quite similar to titanium. In fact, this coefficient for fullydense titanium is $8-10 \times 10^{-6} \mathrm{~K}$, while it is $14-15 \times 10^{-6} \mathrm{~K}$ for most typical BG, including BG 1393 and increases to $17 \times 10^{-6} \mathrm{~K}$ for BG 45 S5 [26]. Consequently, the combination of these BGs appears to be an excellent approach to bear both characteristics, considering, on the one hand, that the BG in contact with Ti has a more compatible tension coefficient and, in addition, a greater capacity to infiltrate the pores of the substrate (for the temperature used in the thermal treatment), then the adherence will be greater. Also, this BG has a Tg below $820^{\circ} \mathrm{C}$, therefore, during heat treatment, it can easily flow and fill the pores better. However, if the outer layer of the coating is made of a more bioactive and microporous BG, 
it will increase the area of contact with the physiological fluid and/or the bioactivity of the implant. Therefore, this is the enhanced combination of BGs, as it has been corroborated by previous studies of the authors [21,41].

In this scenario, it seems to be a critical point to achieve a better approximation to overcome prosthesis problems such as stiffness or stress-shielding, via a balanced introduction of pore content with adequate size, to avoid compromising mechanical behavior. In addition, it is also crucial to improve poor titanium osseointegration, adherence, and homogeneous infiltration, employing bioactive coatings with good adhesion and without fragility problems. In this sense, we have reported previous studies focused on a singular approach that includes the use of controlled porous implants covered with a bilayer coating; the inner layer that is in contact with the titanium substrate that has a greater infiltration capacity, a closer dilatation coefficient compared to Ti, and significant adherence to the pores (BG 1393); and the outer layer (BG 45S5), which exhibits better bioactivity with physiological fluids. However, despite the novelty of these findings and the viability of the proposal, it is still necessary to optimize the porosity of the titanium substrate, improve the tribomechanical balance (rigidity, microhardness, mechanical, and scratch resistance), and at the same time, the biofunctionality (infiltration, structural integrity, and adhesion of the coating).

Thus, the main objective of this work is to evaluate the tribomechanical behavior and in vitro osteointegration capacity of porous titanium substrates coated with this specific bilayer coating. In this case, porous titanium discs were fabricated using a space-holder technique with 50 vol.\% porosity and two pores size ranges: 100-200 and 355-500 $\mu \mathrm{m}$ spacer particles [42-45], as they have already been tested for adequate characteristics to promote infiltration, adhesion, structural integrity, and mechanical balance (stiffness and yield stress). To promote adherence, BG 1393 was used with a CTE such as Ti; however, BG $45 \mathrm{~S} 5$ was placed in the outer layer to promote osseointegration. In vitro experiments were performed in SBF to evaluate bioactivity.

\section{Materials and Methods}

\subsection{Commercially Pure Titanium Substrates}

Porous substrates were manufactured using the space-holder technique (SH) following the protocol already described by the authors [7,46-48]. For this purpose, commercially pure titanium (c.p. Ti) grade IV supplied by SEJOING Materials Co. Ltd. (Seoul, Korea) was used (mean particle size $\mathrm{d}_{[50]}=23.3 \mu \mathrm{m}$ ) [49]. Ammonium bicarbonate $\left(\mathrm{NH}_{4} \mathrm{HCO}_{4}\right)$ (BA), 99\% purity, supplied by Cymit Química S.L. (Barcelona, Spain) of two different range sizes (100-200 and 355-500 $\mu \mathrm{m})$ was used as spacer particles. They were mixed with the c.p. Ti (50 vol.\%), pressed at $800 \mathrm{MPa}$ using an Instron 5505 machine and then, the spacer particles were removed in a furnace under low vacuum conditions $\left(\sim 10^{-2} \mathrm{mbar}\right)$ in two steps, first at $333 \mathrm{~K}$ and then at $380 \mathrm{~K}$, for $12 \mathrm{~h}$ each cycle. Subsequently, the samples were sintered in a molybdenum chamber furnace (Termolab, Agueda, Portugal) under high vacuum conditions $\left(\sim 10^{-5} \mathrm{mbar}\right), 1523 \mathrm{~K}$ for $2 \mathrm{~h}$. Cylindrical discs of $\sim 12 \mathrm{~mm}$ diameter and $5 \mathrm{~mm}$ height were obtained. To perform the different studies, the samples were prepared following a standard metallography procedure on the one side (grinding and mechanicalchemical polishing). As a reference, fully-dense samples (without spacer particles) were fabricated to be compared to those of the porous substrates.

\subsection{Characterization of the c.p. Ti Substrates}

The porosity of the substrates was evaluated using the Archimedes' method [50], from which the percentage of total and interconnected porosity $\left(P_{T}\right.$ and $P_{i}$, respectively) was determined. Furthermore, image analysis (IA) was carried out on optical images acquired with a Nikon Eclipse MA100 N microscope to characterize the equivalent diameter of the pores, Deq, and the shape factor, $F_{f}=4 \pi \mathrm{A} /(\mathrm{PE})^{2}$, where $\mathrm{A}$ is the area of the pores and $\mathrm{PE}$ is the experimental perimeter of pseudo-elliptic pores. For image analysis, Image-ProPlus 6.2 software (Mediacibernectic, Bethesda, MD, USA) was used. 
In addition, scanning electron microscopy images were also acquired with a FEI Teneo microscope (FEI, Eindhoven, The Netherlands) operating at $15 \mathrm{keV}$ for structural characterization. This microscope is equipped with an energy-dispersive X-ray spectroscopy system (EDS-SEM) for compositional analyses. Images were also acquired with a confocal laser microscope (CLM) to measure the roughness of the surface by evaluating parameters such as the arithmetical mean deviation $\left(S_{a}\right)$ and the root-mean-square height $\left(S_{q}\right)$.

Finally, mechanical properties of the porous c.p. Ti substrates, such as the yield strength and Young's modulus, were estimated from the porosity data, using equations already reported in the literature. In particular, dynamic Young's modulus, $E_{d}$, [7] (Equation (1)); Nielsen equation for Young Modulus, $E_{N}$; [51] (Equation (2)) and yield strength, $\sigma_{y}$, [52] (Equation (3)). For these equations, Young's modulus for bulk c.p. Ti grade IV was $\sim 110 \mathrm{GPa}$ [53] and the yield strength of the bulk c.p. Ti grade IV 650 GPa [54].

$$
\begin{gathered}
E_{d}=E_{T i} \times\left(e^{-0.02 \times P_{T}}\right)-0.03 \times E_{T i} \\
E_{N}=\frac{E_{T i} \times\left(1-\frac{P_{T}}{100}\right)^{2}}{1+\left(F_{f}-1\right) \times \frac{P_{T}}{100}} \\
\frac{\sigma_{y}}{\sigma_{T i}}=\left(1.2018 \times e^{-0.043 \times P i}\right)
\end{gathered}
$$

\subsection{Bioactive Bilayer Coatings: Deposition and Characterization}

C.p. Ti substrates were coated with a combination of two different bioglasses, Bioglass ${ }^{\circledR}$ $45 S 5$ and Bioglass ${ }^{\circledR}$ 1393, both commercially available (supplied by SCHOTT Vitrixx). Bioglasses were amorphous powder as received, with a mean particle size of $d_{[50]}=4.5 \mu \mathrm{m}$ and $\mathrm{d}_{[50]}=6.1 \mu \mathrm{m}$ for BG $45 \mathrm{~S} 5$ and BG 1393, respectively [55]. The chemical composition of $\mathrm{BG} 45 \mathrm{~S} 5$ is 45 wt. $\% \mathrm{SiO}_{2}, 24.5$ wt. $\% \mathrm{CaO}, 24.5$ wt. $\% \mathrm{Na}_{2} \mathrm{O}$ and 6 wt. $\% \mathrm{P}_{2} \mathrm{O}_{5}$ [35], while for $\mathrm{BG} 1393$ it is 53 wt. $\% \mathrm{SiO}_{2}, 20$ wt. $\% \mathrm{CaO}, 6$ wt. $\% \mathrm{Na}_{2} \mathrm{O}, 4$ wt. $\% \mathrm{P}_{2} \mathrm{O}_{5}, 12$ wt. $\% \mathrm{~K}_{2} \mathrm{O}$ and 5 wt. \% MgO [56].

The layers of the bioglasses were deposited onto the porous c.p. Ti substrates by dripping sedimentation with a suspension of $0.1 \mathrm{~g}$ of bioglass per $10 \mathrm{~mL}$ of ethanol that was stirred actively and subjected to an ultrasonic bath for $15 \mathrm{~min}$ to avoid sedimentation. Two layers of each bioglass were deposited on each substrate, starting with BG 1393, directly contacting the c.p. Ti substrates and then, BG 45S5 was deposited on the BG 1393. To allow the evaporation of the ethanol, the samples were dried for $24 \mathrm{~h}$ at room temperature after the deposition of each bioglass layer before coating with the next layer. Finally, a low vacuum $\left(\sim 10^{-2}\right.$ mbar $)$ heat treatment was performed on the coated substrates in a Vita Vacumat $600 \mathrm{M}$ furnace, with a heating rate of $20^{\circ} \mathrm{C} / \mathrm{min}$ until $600{ }^{\circ} \mathrm{C}$ and then $40{ }^{\circ} \mathrm{C} / \mathrm{min}$ until $820^{\circ} \mathrm{C}$, a temperature that was held for $5 \mathrm{~s}$, cooling the sample outside the furnace. This heat treatment was selected after trying different conditions, taking into account the chemical composition and critical temperatures of both BGs as well as the fluidity of BG 1393 to favor its infiltration into the macropores. Coating was performed for the two pores range size spacer particles and on the whole cylinder as well as D-shaped samples to determine the infiltration into the pores and thickness of the BG bilayer coating. In the last case, for the coating of the D-shaped, the c.p. Ti substrates were held together with a retractable polymer to achieve a homogeneous coating [21].

To evaluate the coating, SEM and CLM studies were also performed in the top-view to check the homogeneity and general aspect, and in the cross-sectional view to measure the thickness and infiltration of the coating into the pores. Furthermore, the tribomechanical properties of the coated substrates were measured on the surface of the samples using a Microtest machine (MTR3/50-50/NI, Microtest S.A., Madrid, Spain), which allowed loading and unloading tests ( $P$ - $h$ curves) and scratch tests. On the one hand, $P$ - $h$ curves were performed by load control applying $1 \mathrm{~N}$ as maximum load and $10 \mathrm{~s}$ of holding time 
$\left(1 \mathrm{~N} \cdot \mathrm{min}^{-1}\right.$ as applied load rate) using a Vickers indenter. The micro-hardness and Young's modulus of the coated substrates were estimated from the $P$ - $h$ curves using the Oliver and Pharr method [57-60] (Equations (4)-(6)). These results were corrected for by considering changes due to the indenter geometry due to wear or damage due to its use. On the other hand, scratch tests were performed using a Rockwell diamond tip of $200 \mu \mathrm{m}$ diameter and increasing the load from 0 to $3 \mathrm{~N}\left(0.5 \mathrm{~N} \cdot \mathrm{min}^{-1}\right.$ as applied load rate) for $3 \mathrm{~mm}$ of groove scar following the standard [61]. Normal load was recorded continuously during scratching. For each test, a previous scan was performed to evaluate the roughness profile of the surface, from which different roughness parameters were measured: arithmetic average of the absolute values of all points of the profile $\left(R_{a}\right)$, root mean square of the values of all points of the profile $\left(R_{q}\right)$, maximum peak-to-valley height of the entire measurement trace $\left(R_{y}\right)$, and arithmetic average of the maximum peak-to-valley height of the roughness values of five consecutive sampling sections over the filtered profile $\left(R_{z}\right)$. Then, the scratch test was performed; penetration depth, applied load, and path were continuously recorded. From these data, permanent deformation and the estimated elastic recovery of the coating were determined from the real penetration of the depth of the groove scar. Additionally, the observation of the scar provided information on the damage generated on the surface by the applied load (cracking and chipping). All measures, $P-h$ curves, and scratch tests, were performed at least three times.

$$
\begin{gathered}
H=\frac{P_{\max }}{A} \\
E_{e f f}=\frac{S}{\beta \times \frac{2}{\sqrt{\pi} \times \sqrt{A}}} \\
E=\frac{\left(1-v^{2}\right)}{\frac{1}{E_{e f f}-\frac{\left(1-v_{i}^{2}\right)}{E_{i}}}}
\end{gathered}
$$

Finally, in vitro osseointegration was evaluated by measuring bioactivity following the protocol established by Kokubo and Takadama [62] consisting of immersion of coated samples in simulated body fluid (SBF) for 21 days in a polystyrene container at $310 \mathrm{~K}$, renewing the solution at 7, 14, and 21 days. SBF was prepared in the laboratory as in the reference [21]. After this time, the samples were rinsed with deionized water, dried, and characterized to evaluate the formation of hydroxyapatite at the surface as a measure of the bioactivity of the coated samples. For this purpose, inductively coupled plasma (ICP) atomic emission spectrometry (Horiba Jobin Yvon, Horiba LTD, Kyoto, Japan) was employed. Furthermore, SEM images were acquired to observe HA formation, which was also checked by thin film X-ray diffraction (XRD, Bruker, Rivas-VaciaMadrid, Spain) performed on a Bruker D8 Advance A25 diffractometer with a $\mathrm{Cu}$ K $\alpha$ radiation of $0.154 \mathrm{~nm}$.

\section{Results and Discussion}

This section is divided into two subsections according to the different characterizations performed in the development of this work. Therefore, first, the microstructural and porosity characterization of the fabricated porous c.p. Ti is presented, and then the bilayer BGs coating on the substrates is evaluated in terms of microstructure, tribomechanical behavior, homogeneity, adherence, microhardness, and estimation of bioactivity by immersion in SBF.

\subsection{Characterization of the Porous c.p. Ti Substrates}

Figure 1 shows images acquired with different techniques in which the distribution, size, and morphology of the pores can be appreciated. In all these images, in addition to the porosity due to the spacer particles, micro-pores $(<50 \mu \mathrm{m})$ could also be observed that were associated with the fabrication procedure. The $S a$ and $S_{q}$ parameters revealed higher roughness for larger pore sizes, as expected. 

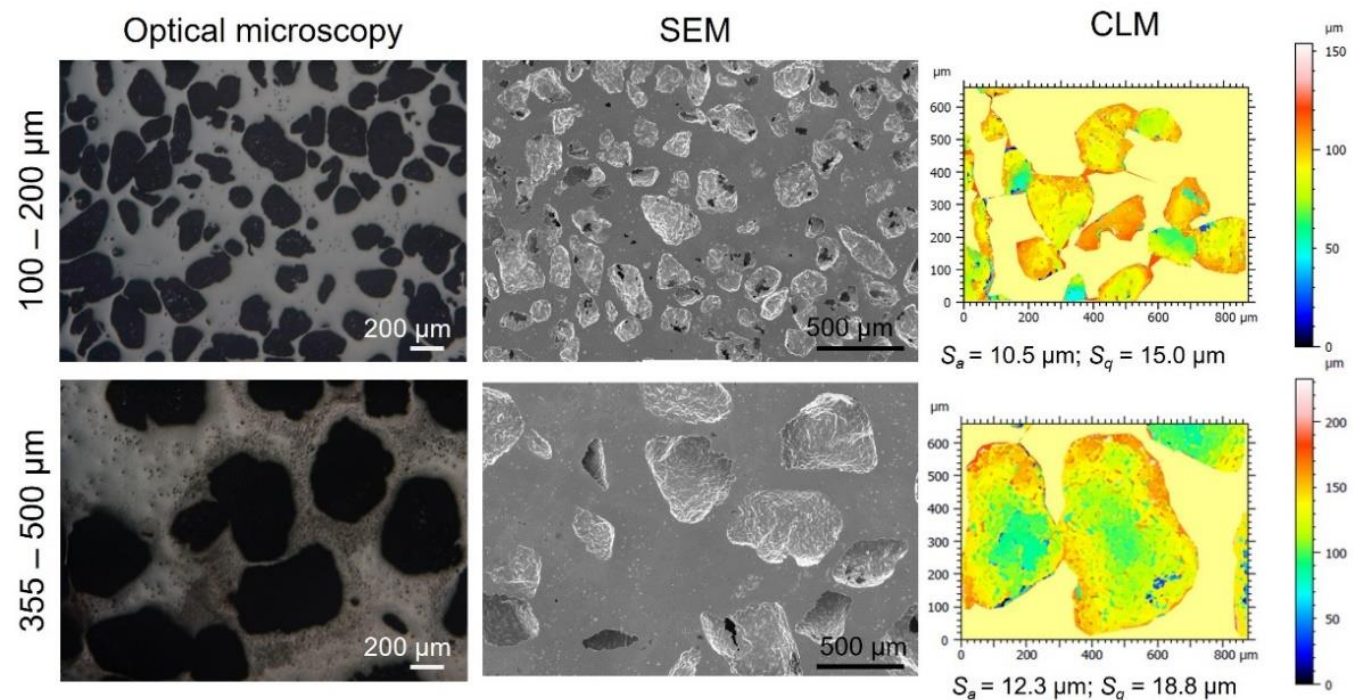

Figure 1. Images of the two pores ranges of size distribution (100-200 and 355-500 $\mu \mathrm{m})$ acquired with optical, SEM, and CLM, respectively. Surface roughness measured by CLM is also indicated.

The porosity and morphology, sizes, and distribution analyses of the pores were completed using the Archimedes' method, which allowed the measurement of not only density, but also total and interconnected porosity. Table 1 summarizes these parameters and the estimated mechanical properties calculated from them, using the Nielsen equations mentioned above. In view of these results, the efficacy of the spacer-holder technique could be confirmed since the porosity and size of the pores agreed with the volume and pore range sizes of the spacer particles used. On the other hand, it is known that mechanical behavior depends on the content and size of the pores. In fact, it could be observed that the pores range sizes mainly affected the yield strength. The results obtained were consistent since, as the Ti matrix of the substrate increased, both $\mathrm{E}$ and $\sigma_{\mathrm{y}}$ increased.

Table 1. Experimental parameters measured by Archimedes' $\left(P_{T}, P_{i}\right)$ and IA $\left(P_{T}, D_{e q}, F_{f}\right)$. Mechanical properties $\left(E_{N}, E_{d}, \sigma_{y}\right)$ estimated from IA data.

\begin{tabular}{ccccccccc}
\hline \multirow{2}{*}{$\begin{array}{c}\text { Pore Range Size } \\
(\mu \mathbf{m})\end{array}$} & \multicolumn{2}{c}{ Archimedes' Method } & \multicolumn{3}{c}{ IA } \\
\cline { 2 - 11 } & $\boldsymbol{P}_{\boldsymbol{T}} \mathbf{( \% )}$ & $\boldsymbol{P}_{\boldsymbol{i}} \mathbf{( \% )}$ & $\boldsymbol{P}_{\boldsymbol{T}} \mathbf{( \% )}$ & $\boldsymbol{D}_{\boldsymbol{e q}}(\boldsymbol{\mu} \mathbf{m})$ & $\boldsymbol{F}_{\boldsymbol{f}}$ & $\boldsymbol{E}_{\boldsymbol{N}}(\mathbf{G P a})$ & $\boldsymbol{E}_{\boldsymbol{d}}(\mathbf{G P a})$ & $\sigma_{y}(\mathbf{M P a})$ \\
\hline $100-200$ & $48.5 \pm 1.1$ & $45.8 \pm 1.4$ & $52.3 \pm 1.2$ & $164 \pm 28$ & 0.72 & $29.3 \pm 2.7$ & $35.4 \pm 1.9$ & 95 \\
$355-500$ & $46.4 \pm 1.0$ & $42.7 \pm 1.1$ & $51.3 \pm 1.0$ & $395 \pm 34$ & 0.75 & $31.3 \pm 2.3$ & $37.1 \pm 1.6$ & 103 \\
\hline
\end{tabular}

\subsection{Deposition of the BG Bilayer and Characterization of the Coated Porous c.p. Ti Substrates}

Figure 2 shows macro-images of a fully-dense (reference substrate without pores) and both spacer particles range sizes used for the manufacture of the porous substrates coated with the two BGs. It could be observed that the coating was more homogeneous and had a good structural entirety when pores were present; even the coating replicated the porous structures, which would mean better infiltration and adhesion of the coatings due to the pores, as checked with D-samples (Figure 3). Fully-dense c.p. Ti substrates showed chipping, corroborating the poor adherence of the coating. 

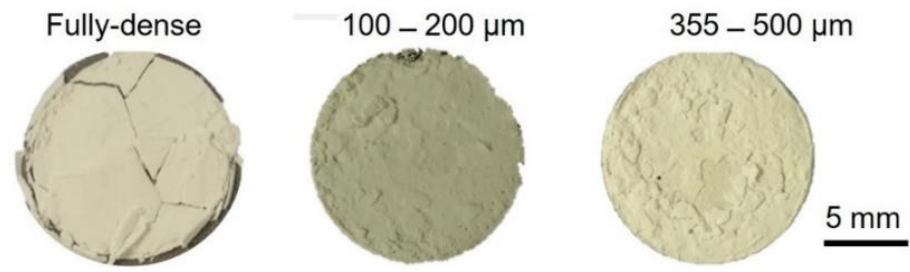

Figure 2. Macro-images of the fully-dense and two pores range sizes (100-200 and 355-500 $\mu \mathrm{m})$ acquired with an optical microscope.

a)

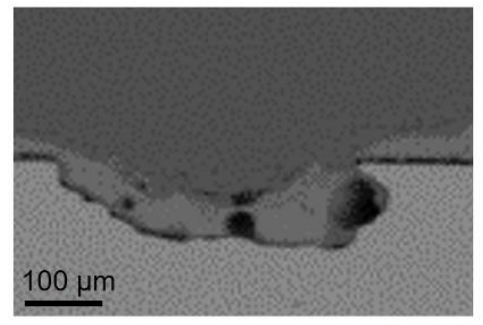

c)

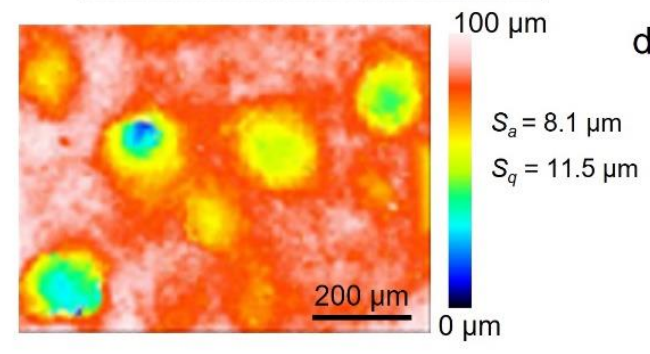

e)

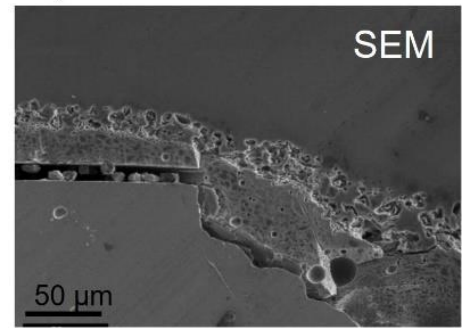

b)

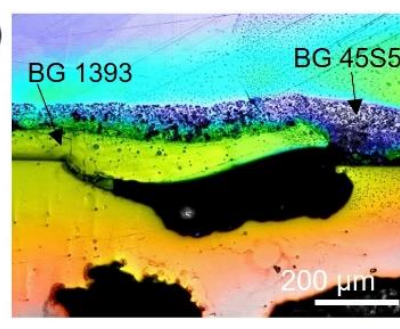

d)

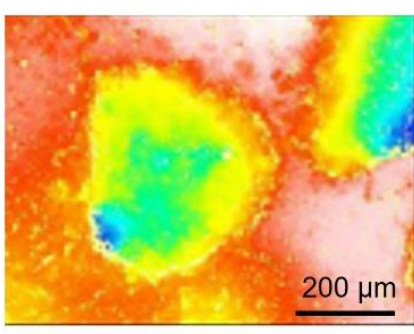

$43 \mu \mathrm{m}$

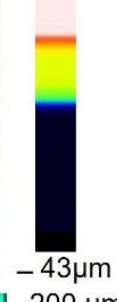

$200 \mu \mathrm{m}$

$S_{a}=22.5 \mu \mathrm{m}$

$S_{q}=29.0 \mu \mathrm{m}$

$0 \mu \mathrm{m}$
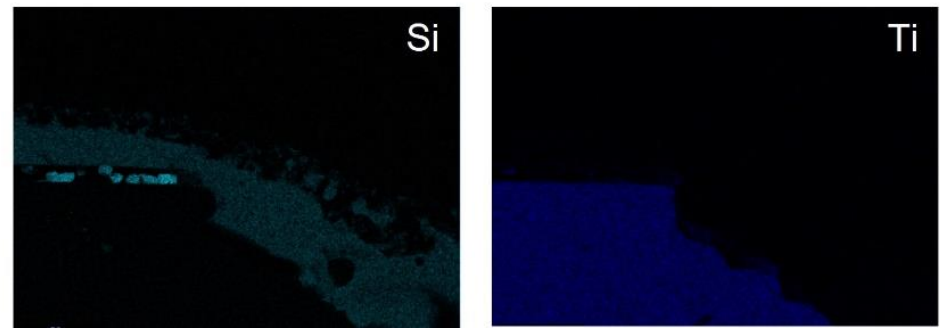

Figure 3. (a) SEM image of the cross-section view of the larger pore size samples; (b) measure of the Scheme 50. vol.\% and 355-500 $\mu \mathrm{m}$ pores range size; (c) top-view CLM image of the 50 vol.\% and 100-200 $\mu \mathrm{m}$; (d) top-view CLM image of the 50 vol.\% and 355-500 $\mu \mathrm{m}$; and (e) SEM image and corresponding Si and Ti mapping acquired by EDS-SEM.

The characterization of the coated substrates was completed by the analysis of the D-shaped substrates to know the infiltration and thickness of the bilayer BGs coating. As an example, Figure 3 displays SEM and confocal images, as well as EDS-SEM of the porous c.p. Ti substrate of $355-500 \mu \mathrm{m}$ porous substrate. The infiltration of the bilayer BG coating into the pores is shown in Figure 3a,b. The SEM image (Figure 3a) revealed a pore completely filled with the coating, while the pore of the CLM image (Figure 3b) was partially filled. Throughout these images, the thickness of the BG layers was measured in a flat area (Ti matrix, without pores. Note that thickness could be higher if under the measure area there was a pore due to the infiltration,), revealing that BG 1393 was a bit thicker than BG $45 S 5$ (73 \pm 5 vs. $54 \pm 4 \mu \mathrm{m}$ ), since BG 1393 had already melted at $820^{\circ} \mathrm{C}$, making infiltration easier into the pores. CLM images acquired on the top-view of both pores range sizes showed the roughness in both cases (Figure 3c,d). It was also checked through compositional analyses performed by EDS-SEM, in which Si, a common element of both BG, $45 \mathrm{~S} 5$ and 1393, was detected inside the pores, on the Ti matrix (Figure 3e). These measures revealed a $19 \mathrm{wt} \%$ and $27 \mathrm{wt} . \%$ of $\mathrm{Si}$ and $\mathrm{Ti}$, respectively. 
In addition, the tribomechanical properties of the coated substrates were evaluated through $P$ - $h$ curves and scratch tests on the surface (top view) of the samples. The $P-h$ curves on both coated porous substrates are shown in Figure 4. The parameters calculated from these curves are summarized in the table included in the Figure 4, comparing to other percentages of porosity and pores range size substrates coated in the same way (BG bilayer) already evaluated by the authors [41]. The micro-hardness of the coatings depends on several aspects such as: (i) the porosity of BG $45 \mathrm{~S} 5$ (on the top), (ii) the hardness of the layer of BG 1393 (between the c.p. Ti substrate and BG 45S5), and (iii) the porosity of the c.p. Ti substrate.
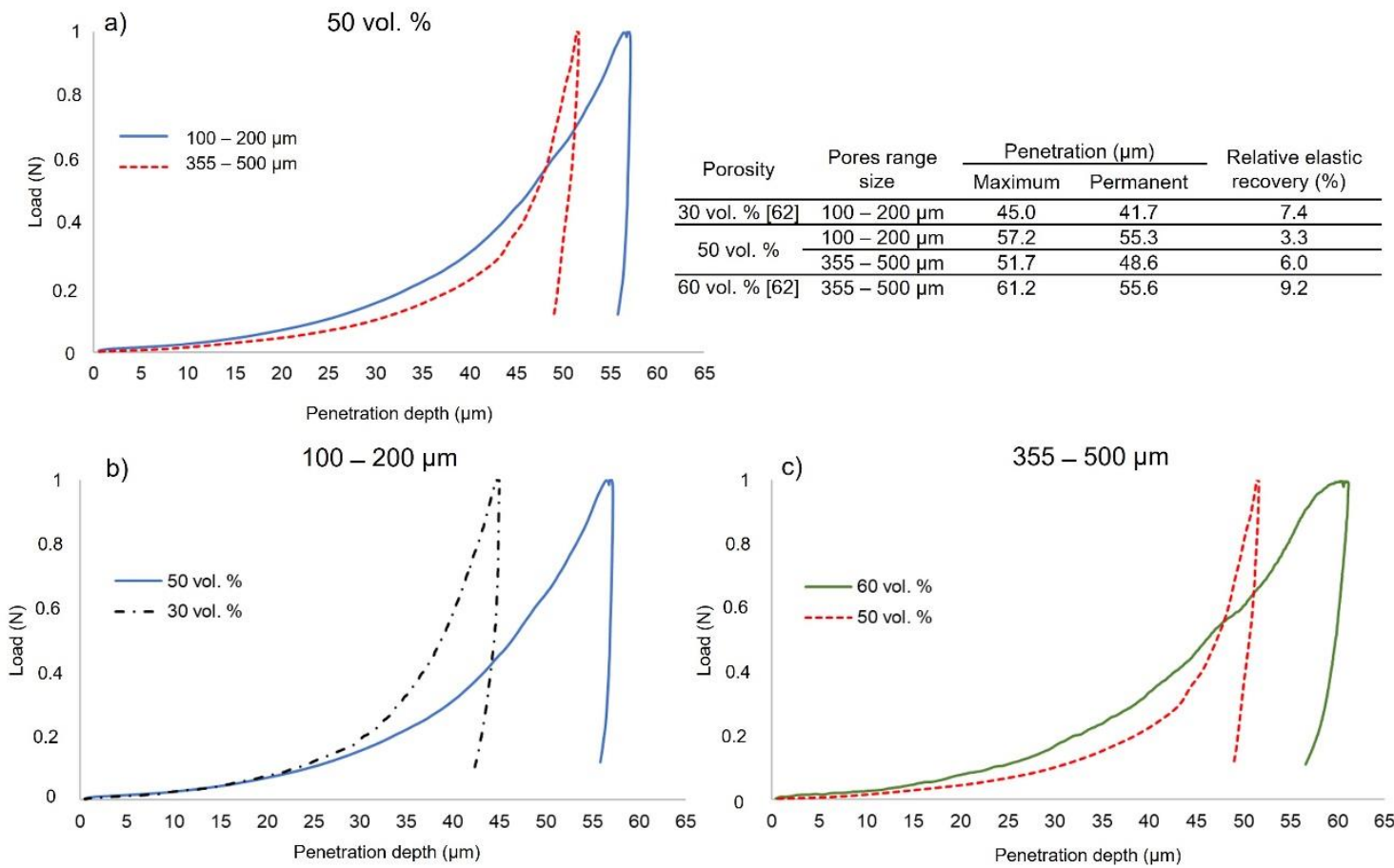

Figure 4. $P$ - $h$ curves of the coated porous c.p. Ti substrates (a) $50 \mathrm{vol} \%$ for the two pores range sizes, (b) 30 and 50 vol.\% and 100-200 $\mu \mathrm{m}$, and (c) 50 and 60 vol. \% and 355-500 $\mu \mathrm{m}$. Inset table: maximum penetration depth and relative elastic recovery for different percentages of porosity and pores range size.

Figure 5 illustrates schemes of the behavior of porous substrates depending on the percentage of porosity and the pores range sizes, observed from the top-view and crosssection of the coated porous c.p. Ti substrates. On the one hand, for a fixed pores range size (i.e., $100-200 \mu \mathrm{m}$ ), the greater the mean free path among pores, the greater the influence the titanium matrix had, since the behavior could be similar to a fully-dense substrate; the effect of the porosity increased, so a higher penetration was observed in the $P$ - $h$ curves. On the other hand, for a fixed percentage of porosity (i.e., 50 vol.\%), the mean free path decreased as the average pore size increased, so harder substrates were detected for smaller pore range sizes. Note that the interpretation of these results was not straightforward because of the variation in the thickness and mechanical properties of both BGs deposited on the porous substrates. In addition, the behavior would also be different depending on whether the indentation got the substrate: Ti matrix or pore. Under these considerations, the results of $P$ - $h$ curves and scratch tests were consistent since penetration depth is related to the thickness of the coating (bilayer BGs). When it is a tenth of the thickness, results are influenced for the next layer, which in our case is BG 1393 (which is more fragile and it can be microcracked after heat treatment) and/or the porous c.p. Ti matrix. It could explain the fact that, for example, on the substrate $50 \mathrm{vol} . \%$ and $100-200 \mu \mathrm{m}$, there is higher $\mathrm{E}$ for 
larger pores, since the penetration depth is higher and the measure should be influenced by the Ti substrate.

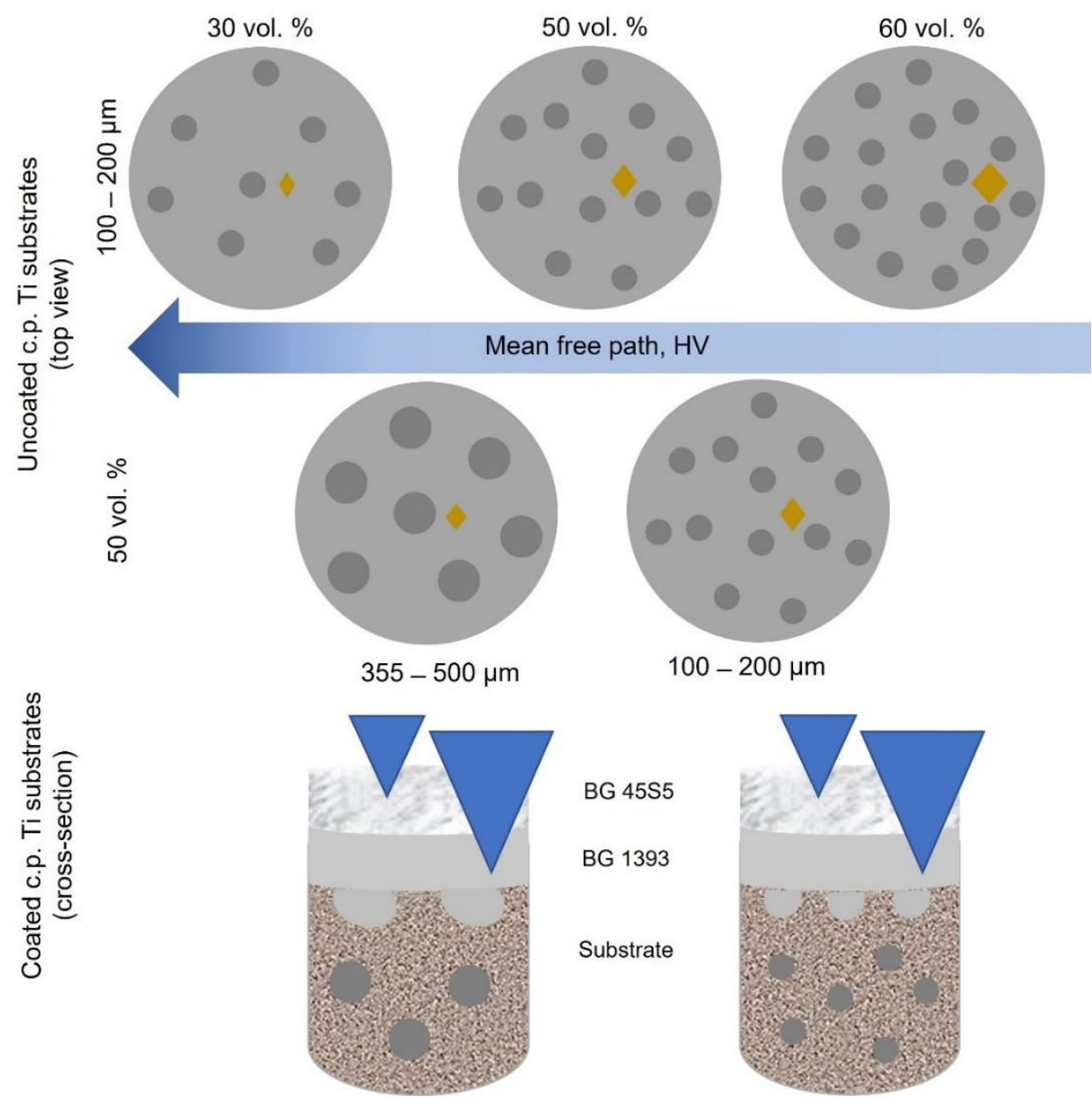

Figure 5. Scheme of the influence of the percentage of porosity and the average size of the pores on the mean free path and mechanical behavior.

Furthermore, from the $P-h$ curves, using Oliver and Pharr methods, the Vickers hardness and Young's modulus were calculated. The results are displayed in Figure 6, which compares not only the substrate studied in this work, but also other porosities and pores range sizes [63]. As discussed before, the hardness was larger for lower porosity and, for the same porosity, like 50 vol.\% bigger pores. The results obtained were consistent with the microporosity of the BG $45 \mathrm{~S} 5$.

Furthermore, scratch tests and curves were performed and are shown in Figure 7 as the main parameters related to the mechanical properties, which are summarized in the figure. It could be observed that, when the applied load increased, the penetration was also higher, as the upper layer of the coating was BG 45S5, which was microporous. The black arrow marks the change in behavior (Figure 7a), which implied $81.07 \mu \mathrm{m}$ of penetration depth and a load of $1.05 \mathrm{~N}$. In the case of the $30 \mathrm{vol} \%$, the change of behavior was observed at $0.65 \mathrm{~N}$ for the smaller pores (Figure $7 \mathrm{~b}$ ). In this case, the elastic recovery was greater because of the effect of micro-porosity. As penetration continued, it started testing BG 1393, which was harder; therefore, the penetration depth decreased. As the application of load continued, the effect of c.p. Ti substrate started to influence the results. The table included in this figure summarizes the average permanent penetration depth and the absolute elastic recovery for the two areas marked with the black arrow in Figure 7a. On the right side, both values were higher. The results are compared to porous substrates fabricated under the same protocol but with different percentages of porosity. It should be noted that when the 
load test increased, depending on the penetration depth, the response was noticed by the upper layer of the coating (BG 45S5), second layer, BG 1393, and/or the c.p. Ti substrate (as it was described before for the $P$ - $h$ curves, see Figure 5). In general, the scratch resistance depends on the micro-porosity of the BG $45 \mathrm{~S} 5$ layer, the hardness of each layer, and/or the type of Ti substrate (metal matrix size). As shown in Figure 7c, it is evident that as the porosity of the substrate increased, the penetration depth also increased. Also, comparing the penetration depth of $50 \mathrm{vol} . \%$ (both range sizes), as it was mentioned for the $P$ - $h$ curves, it decreased (higher resistance to scratch), which could be related to the fact of a higher c.p. Ti matrix substrate.

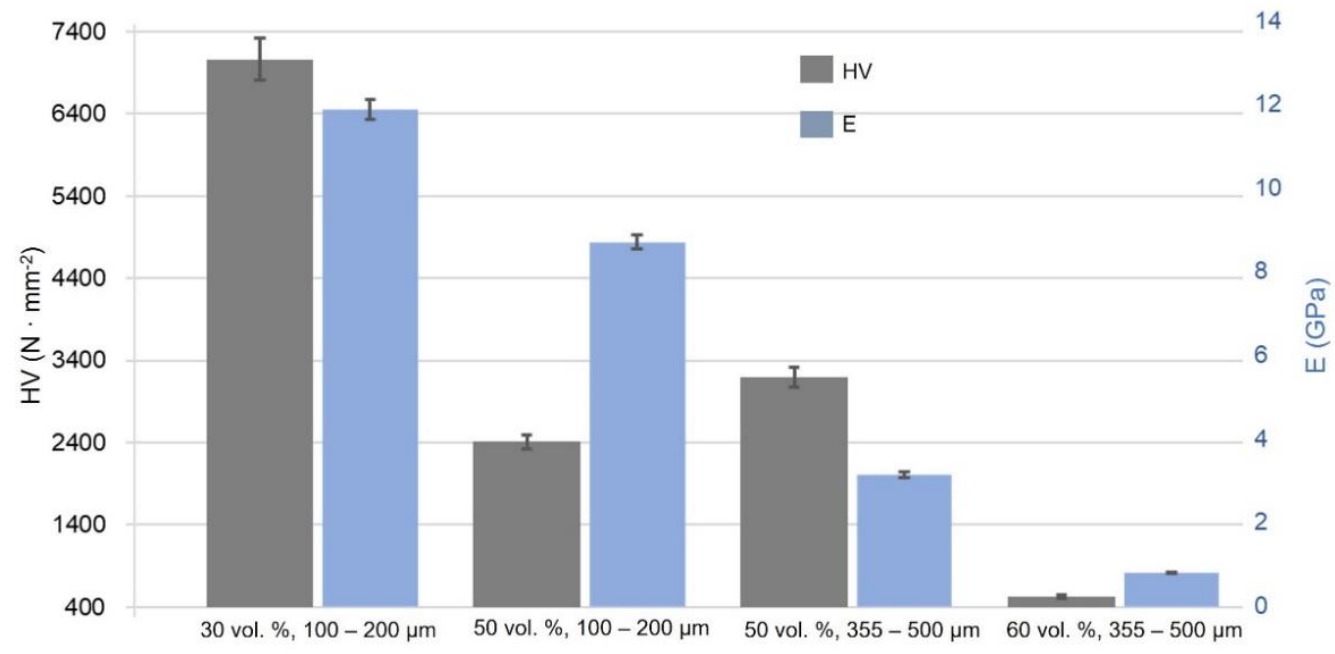

Figure 6. Estimated HV and Young's modulus from the $P$ - $h$ curves.
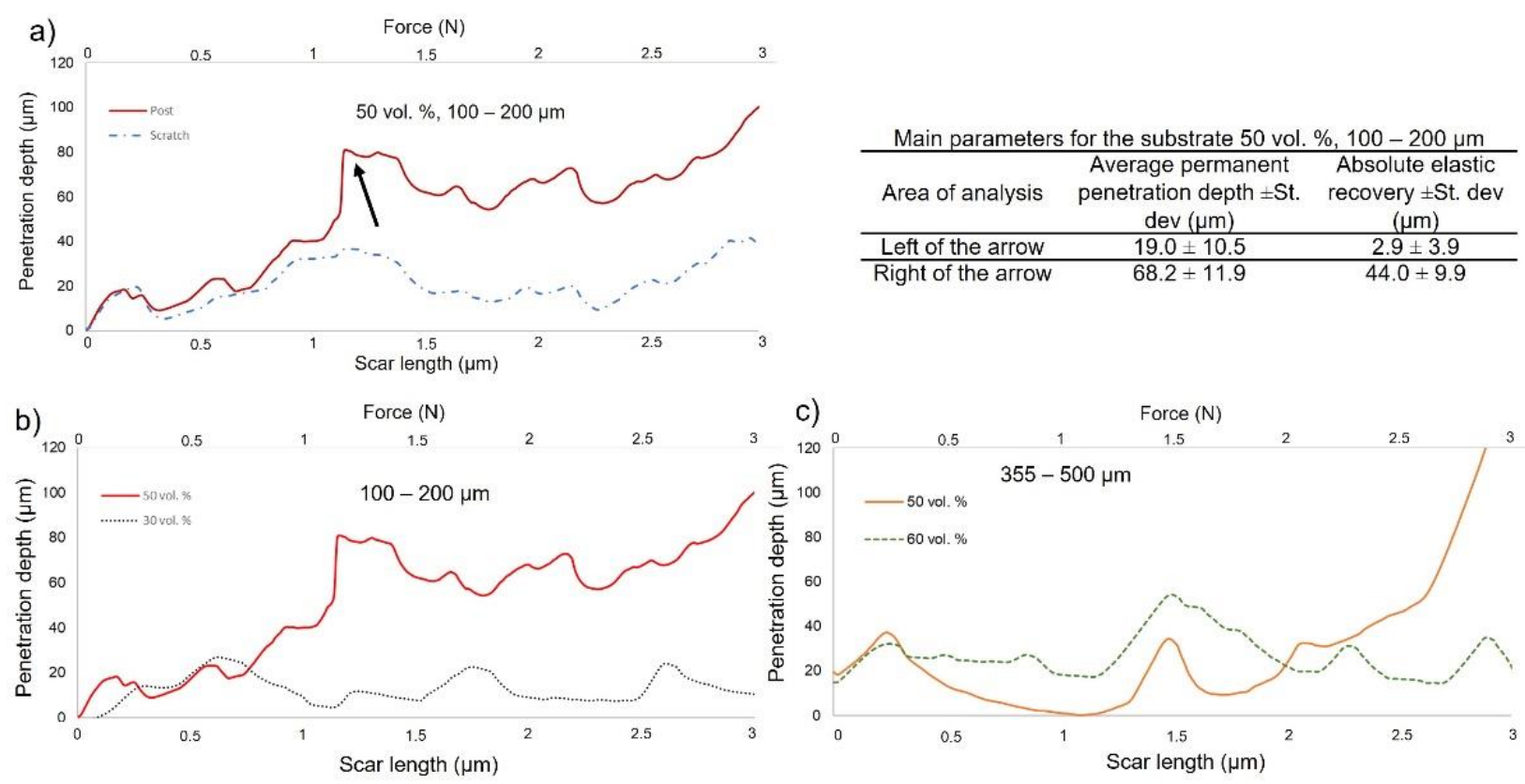

Figure 7. Penetration depth (a) during and after scratch tests for the c.p. Ti substrate with a pore range size of 100-200 $\mu \mathrm{m}$ and 50 vol. \% porosity; (b) post scratch for 100-200 $\mu \mathrm{m}, 30 \mathrm{vol} . \%$ and 50 vol. $\%$ of porosity; and (c) post scratch for $355-500 \mu \mathrm{m}, 50 \mathrm{vol} . \%$ and $60 \mathrm{vol} . \%$ of porosity.

It cannot be forgotten that instrumented microindentation tests ( $P$ - $h$ curves) are static and localized tests (reduced indentation area, local phenomena), which may differ from macro behavior, while scratch tests are dynamic tests and are also performed along a larger area (scratch path). Therefore, parameters such as elastic recovery could not follow a clear 
relationship since the behavior of the coating under different load conditions and rates may be different due to cracks, chipping, etc. In addition to the intrinsic effect of the porosity and nature of the coating, as well as the type of substrate (percentage of porosity and pores size, distribution, morphology), the appearance of cracks and chipping also depends on the conditions of the experiments (static and dynamic), type of indenter (pyramidal and conical), and applied load, among others.

It was also interesting to study the results regarding the roughness of the surface before and after scratch tests. Figure 8 shows them, and the table summarizes the main results. For the same percentage of porosity, $50 \mathrm{vol} . \%$, substrates with larger pores were rougher. First, the roughness results evaluated in the scratch path were consistent with the roughness tendency evaluated with the CLM (Figure 1). However, it is more interesting to see the differences with the roughness of the scratch groove; the results showed a clear increase in $R_{a}$ and $R_{y}$, which could be related to the presence of debris and chipping inherent to the intrinsic fragility of the coating layers. For the same percentage of porosity, as the size of the spacer particles increased, the coating was rougher $\left(R_{a}=7.77 \mathrm{vs} .10 .64 \mu \mathrm{m}\right.$ when comparing smaller and larger pores range sizes, respectively), since it replicated the macro-structure of the substrate. Furthermore, the analysis of the scar revealed the presence of debris and chips, which were greater in the larger pores (see $R_{z}$ and $R_{y}$ in the table for the larger pores range size), since the Ti matrix among the pores was also larger, so adherence was poorer.

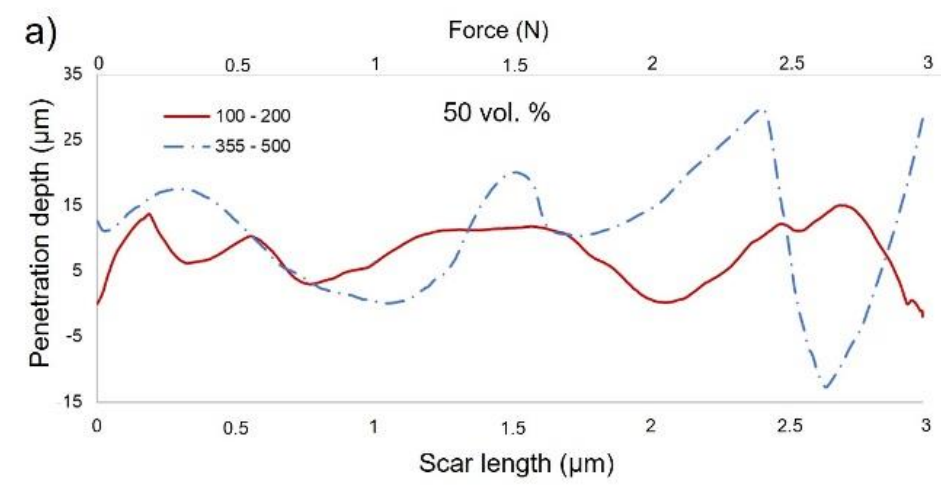

\section{b)}

Measurements of roughness from scratch tests for the 50 vol. $\%$ porous c.p. Ti substrates (all parameters are in $\mu \mathrm{m}$ )

\begin{tabular}{|c|c|c|c|c|c|}
\hline \multicolumn{2}{|c|}{ Pores range size $(\mu \mathrm{m})$} & $R_{a}$ & $R_{g}$ & $R_{3}$ & $R_{y}$ \\
\hline \multirow{2}{*}{$100-200$} & Pre & 7.8 & 8.7 & 13.0 & 16.9 \\
\hline & Post & 21.0 & 62.9 & 41.4 & 41.4 \\
\hline \multirow{2}{*}{$355-500$} & Pre & 10.6 & 14.1 & 17.0 & 42.5 \\
\hline & Post & 29.7 & 44.1 & 130.5 & 130.5 \\
\hline
\end{tabular}

Figure 8. (a) Roughness profile measured before the scratch and (b) characteristic roughness parameters before and after the scratch test.

Finally, to estimate the bioactivity induced by the bilayer, the potential generation of HA was investigated by immersing the substrates in SBF for 21 days. The chemical composition of the medium was obtained by ICP, measuring the concentration of $\mathrm{Ca}, \mathrm{P}$, $\mathrm{Si}$, and $\mathrm{Ti}$ ions before and after 21 days of immersion. According to Table 2, there was an important reduction in the concentration of $\mathrm{Ca}$ and $\mathrm{P}$ ions, suggesting the formation of calcium phosphate salts. In addition, a significant increase in the Si ions was detected. This increase is very important when considering the generation of HA. As previously demonstrated in the literature [21,64], the formation of HA in a BG layer occurs in five steps (Figure 9). The process starts with the leaching of $\mathrm{Ca}^{2+}$ and $\mathrm{Na}^{+}$from $\mathrm{BG}$, which is replaced by $\mathrm{H}^{+}$from the medium. Acidification of $\mathrm{BG}$ causes the breakage of some Si-O bounds, generating $\mathrm{Si}(\mathrm{OH})_{4}$ molecules. The silicic acid can dissolve and repolymerize, creating a Si-rich interface on the BG surface. Finally, the incorporation of $\mathrm{Ca}^{2+}$ and $\mathrm{PO}_{4}{ }^{3-}$ ions into this interface leads to the generation of an amorphous calcium phosphate layer that crystallizes to form HA after the addition of $\mathrm{CO}_{3}{ }^{2-}$ from the medium. Therefore, the increase in Si concentration in SBF from values lower than $0.04 \mathrm{mg} / \mathrm{L}$ in freshly prepared SBF to values of 17.5 and $24.7 \mathrm{mg} / \mathrm{L}$ in samples with $100-200$ and $355-500 \mu \mathrm{m}$, respectively, after 21 days of immersion, was clear evidence of HA formation on the substrate surface. However, the discrepancies in the $\mathrm{Ca} / \mathrm{P}$ ratio with natural $\mathrm{HA}$ obtained by these types of substrates with a porosity of $50 \mathrm{vol} . \%$ were very similar to the one presented by the freshly prepared SBF although with a slightly reduced proportion of $\mathrm{Ca} / \mathrm{P}$. This fact could be 
explained by the amount of $\mathrm{Ca}$ and $\mathrm{P}$ ions required for the formation of HA: five Ca cations consumed against three $\mathrm{P}$ atoms for each HA unit, which would lead to the reduction of the initial $\mathrm{Ca} / \mathrm{P}$ proportion. In addition, these results were in agreement with those calculated for samples with a porosity of $30 \mathrm{vol} . \%$ and $60 \mathrm{vol} . \%$, already described by the authors [21]. The combination of these results pointed to the generation of HA on top of the BG bilayer.

Table 2. Chemical composition of SBF by ICP. Influence of the pore size distribution on the formation of $\mathrm{HA}(\mathrm{Ca} / \mathrm{P}$ ratio).

\begin{tabular}{|c|c|c|c|}
\hline \multirow{2}{*}{ (mg/L) } & \multirow{2}{*}{0 Days } & \multicolumn{2}{|c|}{21 Days } \\
\hline & & $100-200 \mu \mathrm{m}$ & 355-500 $\mu \mathrm{m}$ \\
\hline $\mathrm{Ca}$ & 74.3 & 48.7 & 49.7 \\
\hline $\mathrm{P}$ & 39.2 & 30.2 & 28.1 \\
\hline $\mathrm{Si}$ & $\leq 0.04$ & 17.5 & 24.7 \\
\hline $\mathrm{Ti}$ & $\leq 0.04$ & $\leq 0.01$ & $\leq 0.01$ \\
\hline $\mathrm{Ca} / \mathrm{P}$ & 1.46 & 1.25 & 1.37 \\
\hline Discrepancy (\%) ${ }^{a}$ & 11 & 25 & 18 \\
\hline
\end{tabular}

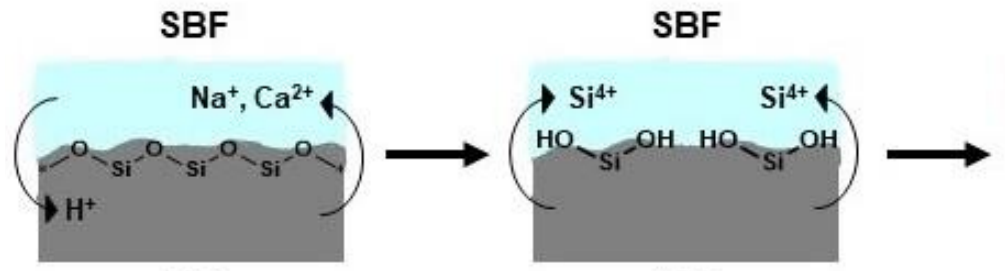

BG
BG
SBF

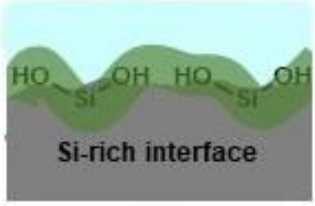

BG

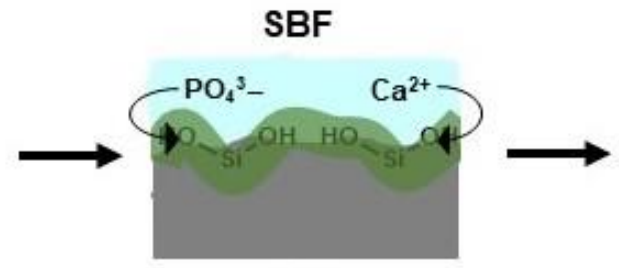

BG

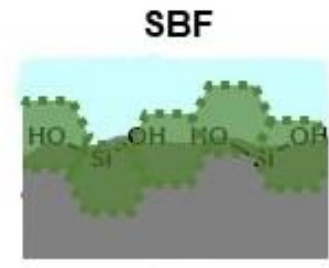

BG

Figure 9. Process of HA formation in BG in the presence of SBF.

HA formation onto BG-coated samples after 7 and 14 days of immersion was already investigated by the authors [21,41,63]. In all cases, the $\mathrm{Ca} / \mathrm{P}$ discrepancy was very high after 14 days, which would mean that the HA is still in the process of formation. Probably, the HA generation mechanism is in the third step, where a Si-rich interface is formed, as the ICP result points out the increment in the Si concentration. Therefore, from our previous experience, carrying out further investigations on samples after 14 days of immersion in SBF would not show relevant information from the final scenario, which is the one that would be potentially used as an application.

Formation of HA on porous c.p. Ti was clear, as shown in Figure 10 for the porous c.p. Ti of the larger pore range sizes. Surface changes were more than evident, since the mentioned substrate was all covered with a rough surface that was different after SBF treatment, in which kinds of characteristic oval pools were formed by salt deposition and crystallization. Furthermore, the XRD diffraction pattern showed peaks that were consistent with the formation of $\mathrm{Ca}_{5}\left(\mathrm{PO}_{4}\right)_{3}(\mathrm{OH})$ and $\mathrm{Ca}_{3}\left(\mathrm{PO}_{4}\right)_{2}$ characteristics of the HA. Indeed, no typical peaks from crystalized BG 45S5, corresponding to $\mathrm{Na}_{2} \mathrm{CaSi}_{2} \mathrm{O}_{6}$ (already published by the authors $[21,63])$, were observed. Note that the SEM images and XRD patterns were acquired in the top-view and, therefore, on the BG $45 S 5$ layer. 

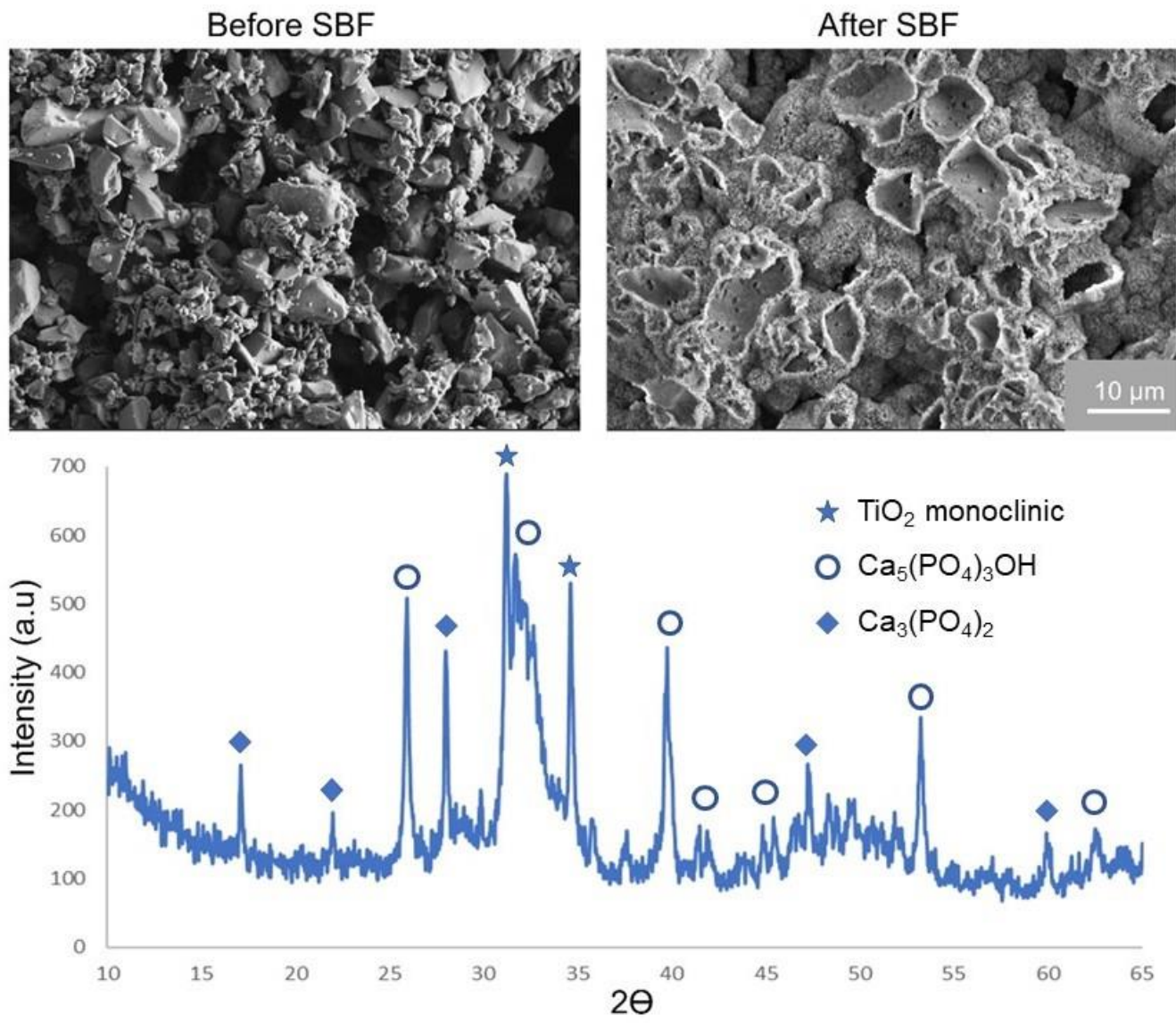

Figure 10. SEM top view images before and after immersion in SBF for the porous c.p. Ti substrate with a pores range size of 355-500 $\mu \mathrm{m}$ and XRD pattern after SBF (21 days in SBF).

\section{Conclusions}

This work summarizes the procedure for manufacturing porous c.p. Ti substrates by the space-holder technique as an efficient way to control the percentage of porosity and characteristics of the pores (morphology, size, and distribution). To enhance biofunctionality, they were coated with a combination of BG 45S5 and BG 1393 layers. Since substrates with $50 \mathrm{vol} . \%$ porosity were already described to exhibit good biomechanical balance, here, two different pores range sizes, $100-200$ and 355-500 $\mu$ m substrates, were coated with the BG. With respect to the results obtained, coated porous substrates presented an improved behavior compared to that of fully-dense reference samples. In addition, compared to previous results, these substrates contain higher porosity and larger pores range size, which could be more recommended since they not only perform better tribomechanical balance (porous c.p. Ti substrate with better mechanical properties, harder coatings, and greater scratch resistance), but also and at the same time, implement biofunctionality (coating infiltrated in larger pores and bioactivity of the coating should be higher). In conclusion, the combination of the bilayer coating BG 45S5-BG 1393 on porous c.p. Ti substrates is a very promising tandem for achieving a desired biomechanical and biofuncional balance.

Author Contributions: Investigation, formal analysis, validation, A.M.B., P.T., F.B. and B.B.; writing - original draft preparation, writing—review and editing, A.M.B., A.A. and B.B.; conceptualization, methodology, project administration, and funding acquisition, A.A., J.A.R.-O. and Y.T. All authors have read and agreed to the published version of the manuscript.

Funding: This research was funded by the Ministry of Science and Innovation of Spain under the grant PID2019-109371GB-I00, by the Junta de Andalucía-FEDER (Spain) through the Projects Ref. US-1259771 and US-1380878, and through the Project PAIDI Junta de Andalucía (Spain) 2020, P20_00671. 


\section{Institutional Review Board Statement: Not applicable.}

Informed Consent Statement: Not applicable.

Data Availability Statement: Not applicable.

Acknowledgments: The authors thank the financial support of the different institutions and to the technician J. Pinto for his support for the tribomechanical tests.

Conflicts of Interest: The authors declare no conflict of interest.

\section{References}

1. Barrios-Muriel, J.; Romero-Sánchez, F.; Alonso-Sánchez, F.J.; Salgado, D.R. Advances in Orthotic and Prosthetic Manufacturing: A Technology Review. Materials 2020, 13, 295. [CrossRef] [PubMed]

2. Statistical Office of the European Communities. Population Structure and Ageing. In Eurostat-Statistics Explain; Statistical Office of the European Communities: Luxembourg, 2021.

3. Kaur, M.; Singh, K. Review on titanium and titanium based alloys as biomaterials for orthopaedic applications. Mater. Sci. Eng. C 2019, 102, 844-862. [CrossRef] [PubMed]

4. Pałka, K.; Pokrowiecki, R. Porous Titanium Implants: A Review. Adv. Eng. Mater. 2018, 20, 1700648. [CrossRef]

5. Wen, C.E.; Yamada, Y.; Shimojima, K.; Chino, Y.; Hosokawa, H.; Asahina, T.; Mabuchi, M. Preparation of biocompatible porous titanium with high strength and ultra-low density. In Proceedings of the Mechanics and Material Engineering for Science and Experiments, Changsha, China, 12 August 2001; pp. 552-556.

6. Torres, Y.; Pavón, J.; Nieto, I.; Rodriguez, J.A. Influence of sintering conditions on the microstructural and mechanical porperties of porous Ti c.p. for biomedical applications. An. Mecánica Fract. 2010, 1, 63-68.

7. Lascano, S.; Arévalo, C.; Montealegre-Melendez, I.; Muñoz, S.; Rodriguez-Ortiz, J.A.; Trueba, P.; Torres, Y. Porous Titanium for Biomedical Applications: Evaluation of the Conventional Powder Metallurgy Frontier and Space-Holder Technique. Appl. Sci. 2019, 9, 982. [CrossRef]

8. Rodriguez-Contreras, A.; Punset, M.; Calero, J.A.; Gil, F.J.; Ruperez, E.; Manero, J.M. Powder metallurgy with space holder for porous titanium implants: A review. J. Mater. Sci. Technol. 2021, 76, 129-149. [CrossRef]

9. Liu, Y.; Rath, B.; Tingart, M.; Eschweiler, J. Role of implants surface modification in osseointegration: A systematic review. J. Biomed. Mater. Res. Part A 2019, 108, 470-484. [CrossRef]

10. Albrektsson, T.; Wennerberg, A. On osseointegration in relation to implant surfaces. Clin. Implant Dent. Relat. Res. 2019, 21, 4-7. [CrossRef]

11. Yazdani, J.; Ahmadian, E.; Sharifi, S.; Shahi, S.; Dizaj, S.M. A short view on nanohydroxyapatite as coating of dental implants. Biomed. Pharmacother. 2018, 105, 553-557. [CrossRef]

12. Novaes, A.B., Jr.; De Souza, S.L.S.; De Barros, R.R.M.; Pereira, K.K.Y.; Iezzi, G.; Piattelli, A. Influence of implant surfaces on osseointegration. Braz. Dent. J. 2010, 21, 471-481. [CrossRef]

13. Saveleva, M.; Vladescu, A.; Cotrut, C.; Van der Meeren, L.; Surmeneva, M.; Surmenev, R.; Parakhonskiy, B.; Skirtach, A.G. The effect of hybrid coatings based on hydrogel, biopolymer and inorganic components on the corrosion behavior of titanium bone implants. J. Mater. Chem. B 2019, 7, 6778-6788. [CrossRef] [PubMed]

14. Bellucci, D.; Salvatori, R.; Anesi, A.; Chiarini, L.; Cannillo, V. SBF assays, direct and indirect cell culture tests to evaluate the biological performance of bioglasses and bioglass-based composites: Three paradigmatic cases. Mater. Sci. Eng. C 2019, 96, 757-764. [CrossRef] [PubMed]

15. Rahaman, M.N.; Day, D.E.; Sonny Bal, B.; Fu, Q.; Jung, S.B.; Bonewald, L.F.; Tomsia, A.P. Bioactive glass in tissue engineering Acta Biomater. 2011, 7, 2355-2373. [CrossRef] [PubMed]

16. Schmitz, S.; Beltrán, A.M.; Cresswell, M.; Boccaccini, A.R. A Structural Comparison of Ordered and Non-Ordered Ion Doped Silicate Bioactive Glasses. Materials 2020, 13, 992. [CrossRef] [PubMed]

17. Bellucci, D.; Veronesi, E.; Dominici, M.; Cannillo, V. On the In Vitro Biocompatibility Testing of Bioactive Glasses. Materials 2020, 13, 1816. [CrossRef] [PubMed]

18. Sergi, R.; Bellucci, D.; Salvatori, R.; Cannillo, V. Chitosan-Based Bioactive Glass Gauze: Microstructural Properties, In Vitro Bioactivity, and Biological Tests. Materials 2020, 13, 2819. [CrossRef]

19. Cannio, M.; Bellucci, D.; Roether, J.A.; Boccaccini, D.N.; Cannillo, V. Bioactive Glass Applications: A Literature Review of Human Clinical Trials. Materials 2021, 14, 5440. [CrossRef]

20. Kaur, G.; Pandey, O.P.; Singh, K.; Homa, D.; Scott, B.; Pickrell, G. A review of bioactive glasses: Their structure, properties, fabrication and apatite formation. J. Biomed. Mater. Res. Part A 2014, 102, 254-274. [CrossRef]

21. Beltrán, A.M.; Begines, B.; Alcudia, A.; Rodríguez-Ortiz, J.A.; Torres, Y. Biofunctional and Tribomechanical Behavior of Porous Titanium Substrates Coated with a Bioactive Glass Bilayer (45S5-1393). ACS Appl. Mater. Interfaces 2020, 12, 30170-30180. [CrossRef]

22. Hench, L.L. The story of Bioglass ${ }^{\circledR}$. J. Mater. Sci. Mater. Med. 2006, 17, 967-978. [CrossRef] 
23. Spirandeli, B.R.; Ribas, R.G.; Amaral, S.S.; Martins, E.F.; Esposito, E.; Vasconcellos, L.M.R.; Campos, T.M.B.; Thim, G.P.; Trichês, E.S. Incorporation of 4555 bioglass via sol-gel in $\beta$-TCP scaffolds: Bioactivity and antimicrobial activity evaluation. Mater. Sci. Eng. C 2021, 131, 112453. [CrossRef] [PubMed]

24. Zafar, M.S.; Farooq, I.; Awais, M.; Najeeb, S.; Khurshid, Z.; Zohaib, S. Bioactive Surface Coatings for Enhancing Osseointegration of Dental Implants. In Biomaterials, Therapeutic and Clinical Applications of Bioactive Glasses; Woodhead Publishing Series; Kaur, G., Ed.; Woodhead Publishing: Sawston, UK, 2019; pp. 313-329. ISBN 978-0-08-102196-5.

25. Jones, J.R. Reprint of: Review of bioactive glass: From Hench to hybrids. Acta Biomater. 2015, 23, S53-S82. [CrossRef] [PubMed]

26. Bellucci, D.; Cannillo, V.; Sola, A. Coefficient of thermal expansion of bioactive glasses: Available literature data and analytical equation estimates. Ceram. Int. 2011, 37, 2963-2972. [CrossRef]

27. Vrouwenvelder, W.C.A.; Groot, C.G.; de Groot, K. Better histology and biochemistry for osteoblasts cultured on titanium-doped bioactive glass: Bioglass $45 \mathrm{~S} 5$ compared with iron-, titanium-, fluorine- and boron-containing bioactive glasses. Biomaterials 1994, 15, 97-106. [CrossRef]

28. Crovace, M.C.; Souza, M.T.; Chinaglia, C.R.; Peitl, O.; Zanotto, E.D. Biosilicate ${ }^{\circledR}$-A multipurpose, highly bioactive glass-ceramic. In vitro, in vivo and clinical trials. J. Non-Cryst. Solids 2016, 432, 90-110. [CrossRef]

29. Mukhopadhyay, S. Bioactive glass-ceramics. Fundam. Biomater. Ceram. 2018, 129-152. [CrossRef]

30. Fiume, E.; Barberi, J.; Verné, E.; Baino, F. Bioactive Glasses: From Parent 45S5 Composition to Scaffold-Assisted Tissue-Healing Therapies. J. Funct. Biomater. 2018, 9, 24. [CrossRef]

31. Rizwan, M.; Hamdi, M.; Basirun, W.J. Bioglass 45S5-based composites for bone tissue engineering and functional applications. J. Biomed. Mater. Res. Part A 2017, 105, 3197-3223. [CrossRef]

32. Baino, F.; Hamzehlou, S.; Kargozar, S. Bioactive Glasses: Where Are We and Where Are We Going? J. Funct. Biomater. 2018, 9 , 25 [CrossRef]

33. Rodrigues, C.; Naasani, L.I.S.; Zanatelli, C.; Paim, T.C.; Azevedo, J.G.; De Lima, J.C.; Fernandes, M.D.C.; Buchner, S.; Wink, M.R. Bioglass 45S5: Structural characterization of short range order and analysis of biocompatibility with adipose-derived mesenchymal stromal cells in vitro and in vivo. Mater. Sci. Eng. C 2019, 103, 109781. [CrossRef]

34. Ingole, V.H.; Sathe, B.; Ghule, A. 12-Bioactive ceramic composite material stability, characterization, and bonding to bone. In Woodhead Publishing Series in Biomaterials; Thomas, S., Balakrishnan, P., Sreekala, M., Eds.; Woodhead Publishing: Sawston, UK, 2018; pp. 273-296; ISBN 978-0-08-102203-0.

35. El-Rashidy, A.A.; Roether, J.A.; Harhaus, L.; Kneser, U.; Boccaccini, A.R. Regenerating bone with bioactive glass scaffolds: A review of in vivo studies in bone defect models. Acta Biomater. 2017, 62,1-28. [CrossRef] [PubMed]

36. Kargozar, S.; Hamzehlou, S.; Baino, F. Can bioactive glasses be useful to accelerate the healing of epithelial tissues? Mater. Sci. Eng. C 2019, 97, 1009-1020. [CrossRef] [PubMed]

37. Bakry, A.S.; Tamura, Y.; Otsuki, M.; Kasugai, S.; Ohya, K.; Tagami, J. Cytotoxicity of $45 S 5$ bioglass paste used for dentine hypersensitivity treatment. J. Dent. 2011, 39, 599-603. [CrossRef] [PubMed]

38. Wang, D.G.; Chen, C.Z.; Ma, Q.S.; Jin, Q.P.; Li, H.C. A study on in vitro and in vivo bioactivity of HA/45S5 composite films by pulsed laser deposition. Appl. Surf. Sci. 2013, 270, 667-674. [CrossRef]

39. Stulajterova, R.; Medvecky, L.; Giretova, M.; Sopcak, T.; Kovalcikova, A. Effect of bioglass $45 S 5$ addition on properties, microstructure and cellular response of tetracalcium phosphate/monetite cements. Mater. Charact. 2017, 126, 104-115. [CrossRef]

40. Ciraldo, F.E.; Boccardi, E.; Melli, V.; Westhauser, F.; Boccaccini, A.R. Tackling bioactive glass excessive in vitro bioreactivity: Preconditioning approaches for cell culture tests. Acta Biomater. 2018, 75, 3-10. [CrossRef]

41. Beltrán, A.M.; Alcudia, A.; Begines, B.; Rodríguez-Ortiz, J.A.; Torres, Y. Porous titanium substrates coated with a bilayer of bioactive glasses. J. Non-Cryst. Solids 2020, 544, 120206. [CrossRef]

42. Domínguez-Trujillo, C.; Ternero, F.; Rodríguez-Ortiz, J.A.; Heise, S.; Boccaccini, A.; Lebrato, J.; Torres, Y. Bioactive coatings on porous titanium for biomedical applications. Surf. Coatings Technol. 2018, 349, 584-592. [CrossRef]

43. Domínguez-Trujillo, C.; Peón, E.; Chicardi, E.; Pérez, H.; Rodríguez-Ortiz, J.A.; Pavón, J.; García-Couce, J.; Galván, J.C.; García-Moreno, F.; Torres, Y. Sol-gel deposition of hydroxyapatite coatings on porous titanium for biomedical applications. Surf. Coat. Technol. 2018, 333, 158-162. [CrossRef]

44. Beltrán, A.M.; Civantos, A.; Dominguez-Trujillo, C.; Moriche, R.; Rodríguez-Ortiz, J.A.; García-Moreno, F.; Webster, T.J.; Kamm, P.H.; Restrepo, A.M.; Torres, Y. Porous Titanium Surfaces to Control Bacteria Growth: Mechanical Properties and Sulfonated Polyetheretherketone Coatings as Antibiofouling Approaches. Metals 2019, 9, 995. [CrossRef]

45. Civantos, A.; Domínguez, C.; Pino, R.J.; Setti, G.; Pavón, J.J.; Martinez-Campos, E.; Garcia-Garcia, F.J.; Rodríguez, J.A.; Allain, J.P.; Torres, Y. Designing bioactive porous titanium interfaces to balance mechanical properties and in vitro cells behavior towards increased osseointegration. Surf. Coat. Technol. 2019, 368, 162-174. [CrossRef]

46. Torres, Y.; Rodriguez, J.A.; Arias, S.; Echeverry-Rendon, M.; Robledo, S.; Amigó, V.; Pavón, J.J. Processing, characterization and biological testing of porous titanium obtained by space-holder technique. J. Mater. Sci. 2012, 47, 6565-6576. [CrossRef]

47. Torres, Y.; Lascano, S.; Bris, J.; Pavón, J.; Rodríguez, J.A. Development of porous titanium for biomedical applications: A comparison between loose sintering and space-holder techniques. Mater. Sci. Eng. C 2014, 37, 148-155. [CrossRef] [PubMed]

48. Muñoz, S.; Pavón-Palacio, J.-J.; Rodríguez-Ortiz, J.A.; Civantos, A.; Allain, J.P.; Torres, Y. On the influence of space holder in the development of porous titanium implants: Mechanical, computational and biological evaluation. Mater. Charact. 2015, 108, 68-78. [CrossRef] 
49. Torres, Y.; Trueba, P.; Pavón-Palacio, J.-J.; Montealegre-Melendez, I.; Rodríguez-Ortiz, J.A. Designing, processing and characterisation of titanium cylinders with graded porosity: An alternative to stress-shielding solutions. Mater. Des. 2014, 63, 316-324. [CrossRef]

50. ASTM C373-14; Standard Test Method for Water Absorption, Bulk Density, Apparent Porosity, and Apparent Specific Gravity of Fired Whiteware Products, Ceramic Tiles, and Glass Tiles. ASTM International: West Conshohocken, PA, USA, 2014.

51. Nielsen, L.F. On strength of porous material: Simple systems and densified systems. Mater. Struct. Constr. 1996, 31, 651-661. [CrossRef]

52. Trueba, P.; Beltrán, A.M.; Bayo, J.M.; Rodríguez-Ortiz, J.A.; Larios, D.F.; Alonso, E.; Dunand, D.C.; Torres, Y. Porous Titanium Cylinders Obtained by the Freeze-Casting Technique: Influence of Process Parameters on Porosity and Mechanical Behavior. Metals 2020, 10, 188. [CrossRef]

53. Shen, H.; Brinson, L. Finite element modeling of porous titanium. Int. J. Solids Struct. 2007, 44, 320-335. [CrossRef]

54. Imwinkelried, T. Mechanical properties of open-pore titanium foam. J. Biomed. Mater. Res. Part A 2007, 81A, 964-970. [CrossRef]

55. Sola, A.; Bellucci, D.; Cannillo, V.; Cattini, A. Bioactive glass coatings: A review. Surf. Eng. 2011, 27, 560-572. [CrossRef]

56. Ali, A.; Ershad, M.; Vyas, V.K.; Hira, S.K.; Manna, P.P.; Singh, B.; Yadav, S.; Srivastava, P.; Singh, S.; Pyare, R. Studies on effect of $\mathrm{CuO}$ addition on mechanical properties and in vitro cytocompatibility in 1393 bioactive glass scaffold. Mater. Sci. Eng. C 2018, 93, 341-355. [CrossRef]

57. Sneddon, I.N. The relation between load and penetration in the axisymmetric boussinesq problem for a punch of arbitrary profile. Int. J. Eng. Sci. 1965, 3, 47-57. [CrossRef]

58. Harding, D.S.; Oliver, W.C.; Pharr, G.M.; Baker, S.P.; Børgesen, P.; Ross, C.A.V. Thin Films: Stresses and Mechanical Properties, V. In MRS Proceedings; Academic: Cambridge, MA, USA, 1995; ISBN 9781558992573.

59. Oliver, W.C.; Pharr, G.M. An improved technique for determining hardness and elastic modulus using load and displacement sensing indentation experiments. J. Mater. Res. 1992, 7, 1564-1583. [CrossRef]

60. Oliver, W.C.; Pharr, G.M. Measurement of hardness and elastic modulus by instrumented indentation: Advances in understanding and refinements to methodology. J. Mater. Res. 2004, 19, 3-20. [CrossRef]

61. C1624-05, A; Standard Test Method for Adhesion Strength and Mechanical Failure Modes of Ceramic Coatings by Quantitative Single Point Scratch Testing. ASTM International: Conshohocken, PA, USA, 2015.

62. Kokubo, T.; Takadama, H. How useful is SBF in predicting in vivo bone bioactivity? Biomaterials 2006, 27, 2907-2915. [CrossRef] [PubMed]

63. Moriche, R.; Beltrán, A.; Begines, B.; Rodríguez-Ortiz, J.; Alcudia, A.; Torres, Y. Influence of the porosity and type of bioglass on the micro-mechanical and bioactive behavior of coated porous titanium substrates. J. Non-Cryst. Solids 2020, 551, 120436. [CrossRef]

64. Eckert, H. Structural characterization of bioactive glasses by solid state NMR. J. Sol-Gel Sci. Technol. 2018, 88, 263-295. [CrossRef] 